\title{
Analysis of Anxiety, Motivation, and Confidence of STEM Students During the COVID-19 Pandemic
}

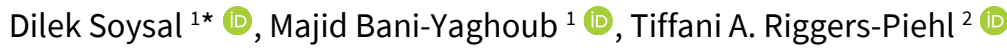

\begin{abstract}
${ }^{1}$ Department of Mathematics and Statistics, University of Missouri-Kansas City, Kansas City, MO, USA ${ }^{2}$ Division of Educational Leadership, Policy and Foundations, University of Missouri-Kansas City, MO, USA *Corresponding Author: dswbz@mail.umkc.edu
\end{abstract}

Citation: Soysal, D., Bani-Yaghoub, M., \& Riggers-Piehl, T. A. (2022). Analysis of Anxiety, Motivation, and Confidence of STEM Students During the COVID-19 Pandemic. International Electronic Journal of Mathematics Education, 17(2), em0684. https://doi.org/10.29333/iejme/11836

\begin{tabular}{|c|c|}
\hline ARTICLE INFO & ABSTRACT \\
\hline Received: 15 Jul. 2021 & The current COVID-19 pandemic has largely impacted the academic performance of several college students. The \\
\hline Accepted: 21 Feb. 2022 & $\begin{array}{l}\text { present study is concerned with the effects of the COVID-19 pandemic on students pursuing a STEM (science, } \\
\text { technology, engineering, and mathematics) degree. We collected weekly survey data ( } \mathrm{w}=9 \text { ) of students ( } \mathrm{n}=53 \text { ) } \\
\text { taking calculus courses during the COVID-19 pandemic. Using the self-reported survey data, we investigated the } \\
\text { temporal variations in the levels of anxiety, motivation, and confidence of STEM students. Studies on temporal } \\
\text { changes to math anxiety are scarce. The present work aims to fill this gap by analyzing longitudinal survey data } \\
\text { associated with math anxiety. Furthermore, using descriptive and inferential statistical methods such as one-way } \\
\text { ANOVA, we analyzed the data with respect to gender and academic level. Our results indicated that male and } \\
\text { freshman/sophomore (F/Sp) STEM students had higher levels of increased anxiety due to COVID-19. Female and } \\
\text { F/Sp STEM students had higher levels of motivation, whereas junior/senior ( } \mathrm{J} / \mathrm{S} \text { ) and male students exhibited } \\
\text { higher levels of confidence. Time series analysis of the data indicated that the levels of motivation and confidence } \\
\text { significantly dropped toward the end of the semester, whereas the level of anxiety increased in all groups. Also, } \\
\text { the use of math resources (such as tutoring and supplemental instruction) has significantly reduced during the } \\
\text { COVID-19 pandemic. }\end{array}$ \\
\hline
\end{tabular}

Keywords: math anxiety, COVID-19 pandemic, STEM students

\section{INTRODUCTION}

Math anxiety has been defined by Tobias and Weissbrod (1980) as "the panic, helplessness, paralysis, and mental disorganization that arises among some people when they are required to solve a mathematical problem" (p. 65) that affects a large percentage of the population. Several factors may contribute to math anxiety including a fear of making mistakes, insufficient mathematical background, teacher and parent comments, attitudes, behaviors, and parental education levels (Sevindir et al., 2014). As the world continues to come to terms with the COVID-19 pandemic, the main challenge many schools are facing is teaching advanced subjects such as calculus online.

The COVID-19 pandemic has affected everyone, including university students. School closures, together with the associated public health and economic crisis, present great challenges for students (García \& Weiss, 2020). With the increase in the number of COVID-19 infections, most university lessons take place virtually, which is especially challenging for STEM (science, technology, engineering, and mathematics) students who are used to hands-on, interactive learning (Hensley et al., 2020). Students are affected because their classes were interrupted, and they were expected to rapidly adapt to the unique expectations of online learning. Forakis et al. (2020) asked their students by responding to a survey to describe the way this transition has affected their academic plans to provide an in-depth look into their intentions. The challenges of COVID-19 impacted the university students' graduations (Saw et al., 2020). Saw et al. (2020) found that nearly $10 \%$ of STEM students had not decided or would not enroll in Fall 2020 due to the pandemic, while $35.5 \%$ of doctoral STEM students, $18 \%$ of master's students, and $7.6 \%$ of undergraduate students delayed their graduation.

The rapidly changing educational landscape caused students to experience extreme stress, emotional exhaustion and frustration, average absenteeism, a somatic burden, and laziness while learning Calculus (Casinillo \& Casinillo, 2020). Mendoza et al. (2021) analyzed the levels of anxiety in university mathematics students studying at the Universidad Nacional de Chimborazo (UNACH) during the Fall 2020 academic semester. The results of their study showed a statistically significant difference in students' understanding of virtually presented content, which correlated to increased levels of math anxiety during the COVID-19 pandemic. Therefore, the pandemic has contributed to mounting anxiety and stress among many STEM students (Alemany-Arrebola et al., 
2020). In the present study, we analyze the time series data of math anxiety throughout the summer 2020 semester. Specifically, we investigate how the levels of math anxiety of calculus (II and III) students changed during the pandemic.

Online learning has disrupted the educational environment many students are accustomed to. Serhan (2020) found that many students were not satisfied with their learning experience during the initial transition to online learning in March 2020. His results indicated that students negatively perceive the use of Zoom and believe it has a negative effect on their learning outcomes and their motivation to learn. Online learning might demotivate students and disincentivize them from watching lectures synchronously; however, student anxiety levels are likely to increase if they miss classes because it is challenging to follow up on difficult calculations independently. Additionally, students' internet connections may be unreliable, making it impossible to continue watching their lessons. Notably, internet connectivity problems disproportionately affect rural students and negatively impact their learning experience (Hampton et al., 2020). Sabates et al. (2021) estimated the learning loss during the three-month transition period from face-to-face learning to online learning in Ghana was $66 \%$ of previous learning gains in foundational numeracy. According to their estimate, the widening gaps in learning losses are due to a lack of home learning support as well as a lack of home learning resources.

Serhan's (2020) finding that synchronous learning decreased student's academic motivation may explain the increased incidence of math anxiety during the COVID-19 pandemic. Mubeen and Reid (2014) explored how motivation relates to selfefficacy, self-concept, confidence, and self-esteem in an educational setting. The researchers found that motivation positively correlates with strong feelings of self-efficacy and self-esteem-two factors that protect against academic anxiety. Thus, low motivation is associated with poor self-efficacy and increased academic anxiety. However, these studies do not measure the level of motivation and confidence as a function of time. The main objective of the present study is to investigate temporal variations in students' levels of motivation, anxiety, and confidence during the COVID-19 pandemic. We also analyze the effects of COVID-19 on students throughout the semester.

Poignantly, student's development of motivation, self-efficacy, and confidence depends on their teachers' capacity to understand, anticipate, and deal with students' ideas about mathematics and mathematical thinking within the context of the world at large (Voica et al., 2020). When the pandemic struck the country, teachers quickly adapted their teaching methods to be as effective as possible (Midcalf \& Boatwright, 2020). In a course on differential calculus, Jungic (2020) found that the level of anxiety student's experienced decreased when facts and statistics about the pandemic were integrated into course exercises. Therefore, to bolster student's self-efficacy and decrease feelings of academic anxiety, Jungic (2020) suggested a new approach that incorporates acknowledgment of the current pandemic in mathematics exams.

Math anxiety can affect people of any age, especially when their situation changes drastically. Many students are affected by anxiety because they lack the proper channels to divert their stress. The pandemic has made it more difficult to redirect stress while simultaneously introducing a number of new challenges (Marpa, 2021). Within the scope of online learning, some of these challenges include communication difficulties that make it easier to misunderstand information and more difficult to ask questions. Reinhold et al. (2021) found that maintaining a positive attitude towards synchronous learning is key to buffering students' stress during this pandemic. A positive attitude corresponds to the more productive redirection of stress and less academic anxiety.

While existing research confirms an increase in math anxiety associated with the current COVID-19 pandemic, a number of questions remain unanswered. The current study seeks to understand how the motivation, anxiety, and confidence of STEM students change during the semester, how these variables defer with respect to academic level and gender, and how the COVID19 pandemic has influenced STEM students' learning environment and utilization of supplemental resources.

If we draw a comparison between the COVID-19 pandemic and the Spanish flu in 1918-1920, real-time communication tools have made it easier to continue life as normal. Recent technological developments have made synchronous learning accessible for many students, making learning mathematics online easier. There are various tools and resources that make it easier to teach calculus and pay special attention to the needs of students during this period of isolation. Real-time communication tools such as Zoom ensure that students are engaged. Contact time is precious and synchronous learning ensures maximum participation in lessons. The pandemic has created feelings of isolation in students used to the collaborative approach used in higher-level math classes (Ng et al., 2020).

Fortunately, real-time learning platforms make it possible to reinforce this collaborative teaching approach. Additionally, online resources like YouTube and Kahn Academy offer additional instruction that may temporarily stand in for in-person resources, like office hours and tutoring. Amidst the rapid transition to online learning at the start of the pandemic, mathematics support/tutoring centers also moved their services online (Johns \& Mills, 2021). Furthermore, concerning the future of online tutoring, roughly $13 \%$ of mathematics center administrators claimed they would not continue due to limited student utilization and a personal preference for face-to-face tutoring (Johns \& Mills, 2021).

In the present study, we assess student utilization of traditional educational resources like private tutoring and digital office hours and compare it to the utilization of other resources in light of the current COVID-19 pandemic. The rest of this paper is organized as follows. In the next section, we provide an outline of the methodology for surveying the students and analyzing the data. Then we provide the main results of the time series analysis of the survey data. Finally, we discuss our main results and provide concluding remarks. 
Table 1. The demographic characteristics of Calculus II and Calculus III students

\begin{tabular}{lccccccc}
\hline & & Calculus II & & \multicolumn{2}{c}{ Calculus III } \\
\hline & Female & Male & Total & Female & Male & Total & Grand total \\
\hline Freshman/sophomore & 11 & 14 & 30 & 3 & 2 & 5 & $\mathbf{3 5}$ \\
\hline Junior/senior & 2 & 9 & 6 & 3 & $\mathbf{6}$ & $\mathbf{1 1}$ & $\mathbf{1 8}$ \\
\hline Grand total & $\mathbf{1 3}$ & $\mathbf{2 3}$ & $\mathbf{3 6}$ & $\mathbf{5 3}$ \\
\hline
\end{tabular}

\section{MATERIALS AND METHODS}

\section{Participants}

Every week, we surveyed $n=53$ STEM students enrolled in Calculus II and Calculus III courses during the COVID-19 pandemic (total of 9 weeks, see Table 1). The participants were STEM students of the Math Department at the University of Missouri-Kansas City (UMKC) in the summer 2020 semester. Students met four times a week (total of 7 hours and 20 minutes per week) in Calculus II and Calculus III courses.

\section{Course Format}

COVID-19 became a worldwide pandemic in mid-March 2020. Consequently, UMKC suspended in-person class sessions and resumed them in an online synchronous format at their regular meeting times. Due to the lack of online teaching experience among faculty, the school had a dedicated team of e-Learning and Information Systems personnel working closely with faculty to facilitate a speedy transition so that the students could finish the semester successfully under these unusual COVID-19 circumstances.

Students were given housing and food discounts at UMKC. Discount and refund policies also applied to other areas of the school, such as parking, the recreation center, cancellation and late penalties, and financial charges. Students with extenuating circumstances will be allowed to challenge the decisions of school administration through a formal process. Because the situation was so serious, the school advised students to wear masks, socially isolate, and avoid small and big groups.

Campus and academic restrictions-campus closures and online learning, remained in place for the whole of Summer 2020. Thus, Calculus II and III were taught for the first time in the Summer of $2020 \mathrm{in}$ an online synchronous style. Previously these classes had only been available in person at UMKC.

Calculus II and III classes took place Monday through Thursday in two, 50-minute periods with a 10-minute break in between. Zoom was used for all classes and office hours. Each of these classes was worth four credits. The passing grade in the previous grading method was 60\%; however, due to COVID-19, it was reduced to 55\%. In the drop-fail-withdraw (DFW) rate, $17.7 \%$ of Calculus III students failed, while 0\% dropped and withdrew. 29.4\% of Calculus II students failed, while $5.9 \%$ dropped out and $0 \%$ withdrew.

Many courses moved to online and were assessed online, which could have influenced students' opportunities to cheat (Lancaster \& Cotarlan, 2021). The exams were timed and designed in a way that reduced the chance of academic dishonesty. Their exam solutions were to be uploaded to an online education site (Canvas) by the student. Exams and homework assignments were often graded within a week. The multiple-choice online quizzes were instantly graded by the Pearson platform My Math Lab.

In Calculus II, students studied techniques of integration, applications of the definite integral, improper integrals, sequences and series, power series, Taylor series and convergence, and analytic geometry in calculus. In Calculus III, students studied vectors, solid analytic geometry, vector functions and multiple variable functions, partial derivatives, multiple integrals, line and surface integrals with their applications.

For the first time, these two classes were offered as online synchronous courses. Some students came from different states in the United States, and some were attending these classes from their native country. For a few students who did not live in the United States, the time zone was particularly problematic.

\section{Instruments}

We utilized a questionnaire inspired by chapter six of Creswell's (2011) Educational Research and applied temporal and statistical analysis to the collected responses. The survey's items were created using best practices as guided by DeVellis and Thorpe (2021) and Dillman et al. (2009).

We designed an online survey accessible through the "Quiz" tab of students' Calculus II and Calculus III canvas sites. The survey included a series of six questions (see Appendix A) developed by us that assessed students' anxiety in relation to their assignments, exams, Zoom meetings, level of motivation and confidence, and usage of additional resources like supplement instruction, tutoring, etc. during COVID-19. Student responses were collected via Canvas once a week for the eight-week duration of the 2020 summer semester and one week prior to the beginning of the semester. The survey results were collected and complied with using Canvas each week. The results were then given to an expert in mathematics education for determination of the validity and clarity of the data. 


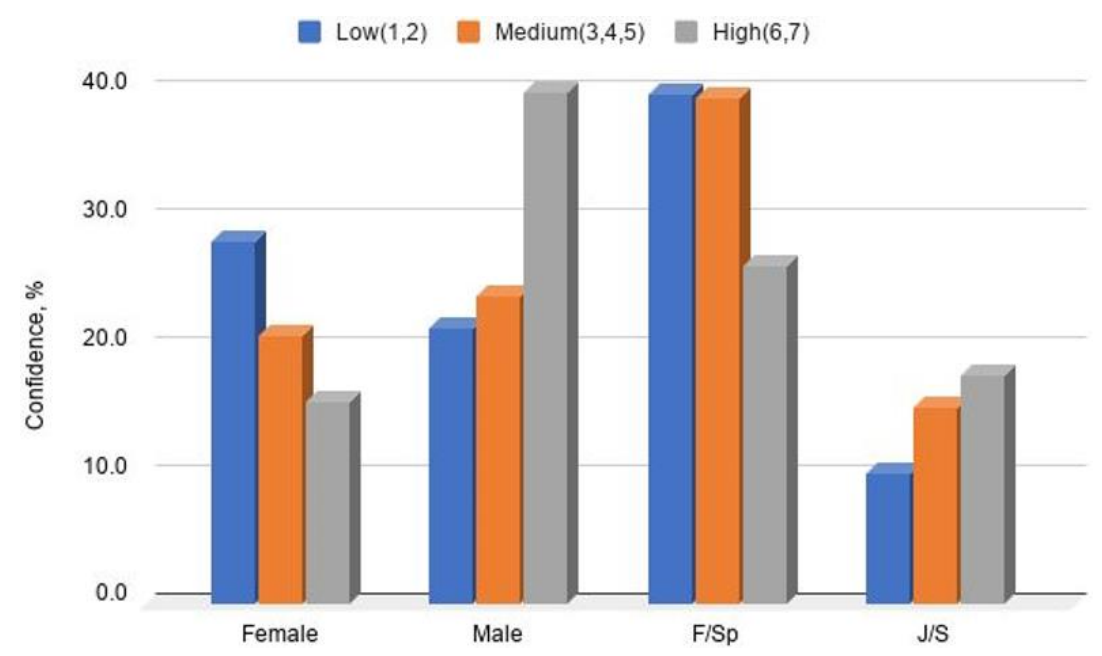

Figure 1. Measures of confidence with respect to gender and level of education

\section{Data Preparations}

At the end of the summer semester, we prepared the data for time series analysis, descriptive statistics, and hypothesis testing. Due to the low number of participants, we combined data of both calculus classes for all statistical analyses performed in this study.

The weekly survey asked students to rank experiences on a numerical scale. For example, question 5 asked "How confident are you today that you will pass this class with a grade B or better? (1=not confident at all, $7=$ =very confident)." After compiling nine weeks of student responses in Qualtrics, we prepared and organized the data for statistical analysis by selecting and using MS Excel software. Data were cleaned (non-essential data, such as timestamps and duplicate information from across the nine weeks, e.g., student numbers were removed) and we assigned numeric codes to each response option as needed. While coding student responses to complex questions, we broke responses into categories. For example, for question 5 we created three categories low confidence (scores 1-2), medium confidence (scores 3-5), and high confidence (scores 6-7). Students' responses to yes or no questions were coded dichotomously such that "yes" was coded as 1 and "no" as 0 . Then we summed the coded data within groups and weeks and organized these values in tables. Next, we calculated these values as percentages and graphed them according to the time series.

Next, we methodically entered the data into an MS Excel spreadsheet and descriptive statistical analyzes were performed. After statistical analysis, the results were reported as figures and demographic data like gender and the academic level was plotted against confidence, motivation, and the effects of COVID-19 on self-reported math anxiety. Next, the practical meaning of these results was elucidated and discussed in further detail.

\section{Statistical Methods}

This study used weekly survey data collected from 53 (34 males and 19 females) undergraduate students enrolled in Calculus II and Calculus III courses during Summer 2020 to investigate rates of math anxiety in the widths of the COVID-19 pandemic. Student responses were collected via weekly Canvas surveys each week of the eight-week summer semester and one week prior to the beginning of the semester. Thus, we had a nine-week data set. This data set allowed us to visually inspect temporal changes in the student's anxiety levels throughout to nine-week study duration.

The prepared data was then analyzed using Statistical MS Excel for conducting descriptive analysis of the data, inferential statistical methods, like one-way ANOVA, were further used, as well as time series analysis.

Descriptive statistics were used to generate tables and graphs of data collected in this study. The analyses were conducted using the ANOVA test for statistical computing and the results of which are presented. To determine whether the hypotheses were supported, we examined the significance of individual paths and the global fit of the model to the observed data.

\section{RESULTS}

\section{Descriptive Statistics}

Descriptive statistical analysis suggested that the COVID-19 pandemic may have contributed to increased levels of math anxiety. Figure 1 shows that male and F/Sp STEM students had higher levels of confidence within their groups. Figure 2 shows that female and F/Sp STEM students had higher levels of motivation within their groups. Figure 3 shows that more male and F/Sp STEM students expressed an increase in math anxiety due to COVID-19. The proportions of male and F/Sp STEM students with high levels of confidence are substantially higher than those with medium or low confidence (Figure 1). The proportion of female STEM students with high levels of motivation are more than males with low or medium levels of motivation (Figure 2). There are higher proportions of male and F/Sp STEM students who expressed increased math anxiety due to COVID-19 (Figure 3). 
40.0

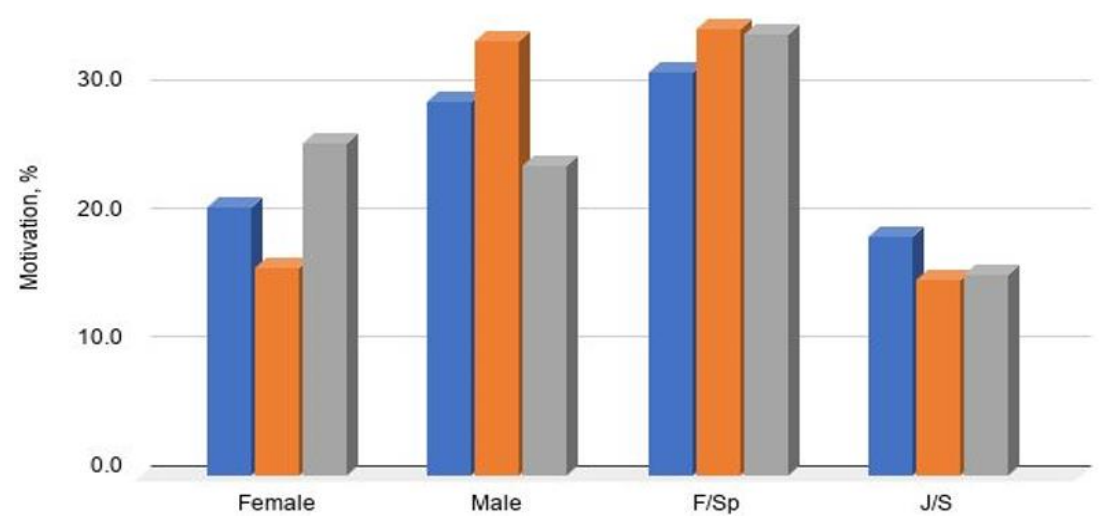

Figure 2. Measures of motivation with respect to gender and level of education

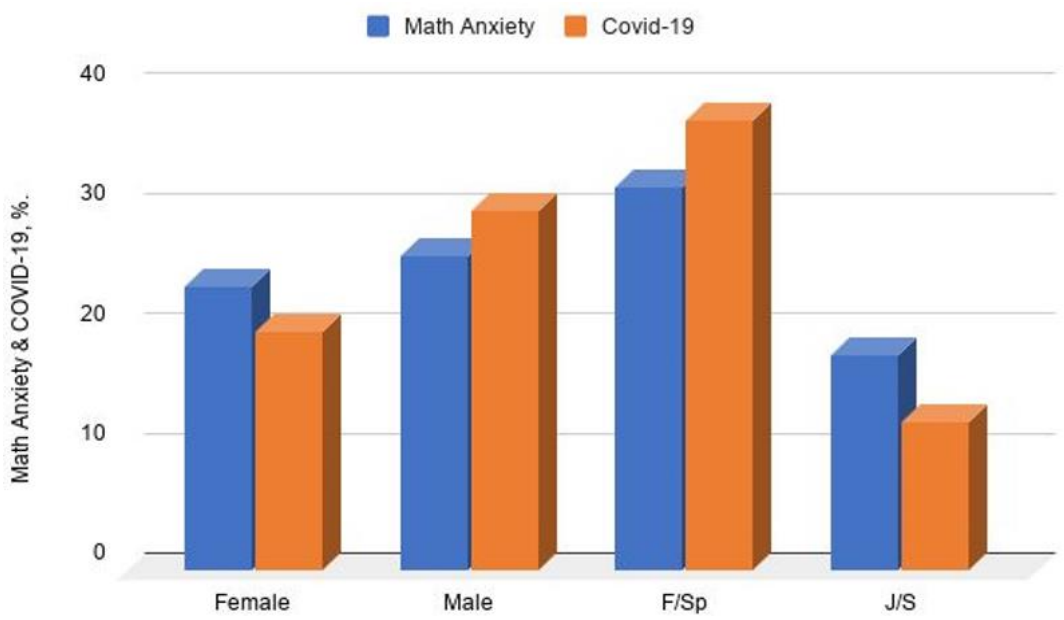

Figure 3. Measures of anxiety with respect to gender and level of education

Table 2. One-way ANOVA test results indicate a significant difference in the mean level of math anxiety with respect to gender

\begin{tabular}{|c|c|c|c|c|c|c|c|}
\hline & SV & SS & df & MS & $\mathbf{F}$ & p-value & FC \\
\hline \multirow{3}{*}{ Did you have any math anxiety this week? } & Between groups & $2,062.96$ & 1 & $2,062.96$ & 7.79 & 0.01 & 4.49 \\
\hline & Within groups & $4,283.64$ & 16 & 264.92 & & & \\
\hline & Total & $6,301.61$ & 17 & & & & \\
\hline
\end{tabular}

Note. SV: Source of variation; SS: Sum of squares; df: Degree of freedom; MS: Mean squares; F: F-value; FC: F critical value

Table 3. One-way ANOVA test results indicate that the COVID-19 pandemic has significantly increased the mean level of math anxiety

\begin{tabular}{|c|c|c|c|c|c|c|c|}
\hline & SV & SS & df & MS & $\mathbf{F}$ & p-value & FC \\
\hline \multirow{3}{*}{ Did COVID-19 increase your math anxiety? } & Between groups & 368.11 & 1 & 368.11 & 9.17 & 0.01 & 4.49 \\
\hline & Within groups & 642.47 & 16 & 40.15 & & & \\
\hline & Total & $1,010.58$ & 17 & & & & \\
\hline
\end{tabular}

Note. SV: Source of variation; SS: Sum of squares; df: Degree of freedom; MS: Mean squares; F: F-value; FC: F critical value

\section{Hypothesis Testing}

The one-way ANOVA test applied to the nine-week data set helps us understand temporal variations in students' levels of motivation, anxiety, and confidence during the COVID-19 pandemic. Students' questionnaire responses indicate a relationship between gender and self-reported anxiety levels throughout the semester, see Table 2 . The inferential analysis based on the gender variable showed significant differences $(p<0.05)$ between male and female students.

Table 3 summarizes the results of one-way ANOVA with respect to the effect of COVID-19 on math anxiety. Specifically, the inferential analysis based on the academic level showed significant differences $(p<0.05)$ between the average responses of $F / S p$ and J/S students to the question "Did COVID-19 increase your math anxiety?"

Similarly, Table 4 is a summary of ANOVA results with respect to gender and student motivation. The inferential analysis showed significant differences $(p<0.05)$ between male and female students for the average levels of motivation. This was demonstrated by variable responses to the question "How would you rate your desire to study this week?" by gender. 
Table 4. One-way ANOVA test results indicate a significant difference among groups with regard to motivation

\begin{tabular}{|c|c|c|c|c|c|c|c|}
\hline & SV & SS & df & MS & $\mathbf{F}$ & p-value & FC \\
\hline \multirow{3}{*}{ How would you rate your desire to study this week? } & Between groups & 25.85 & 1 & 25.85 & 9.46 & 0.002 & 3.87 \\
\hline & Within groups & $1,010.45$ & 370 & 2.73 & & & \\
\hline & Total & $1,036.30$ & 371 & & & & \\
\hline
\end{tabular}

Note. SV: Source of variation; SS: Sum of squares; df: Degree of freedom; MS: Mean squares; F: F-value; FC: F critical value

Table 5. One-way ANOVA test results indicate a significant difference among groups with regard to confidence

\begin{tabular}{|c|c|c|c|c|c|c|c|}
\hline & SV & SS & df & MS & $\mathbf{F}$ & p-value & FC \\
\hline \multirow{3}{*}{$\begin{array}{l}\text { How confident are you todat that you will pass this } \\
\text { class with a grade B or better? }\end{array}$} & Between groups & 15.92 & 1 & 15.92 & 5.71 & 0.02 & 3.87 \\
\hline & Within groups & $1,034.82$ & 371 & 2.79 & & & \\
\hline & Total & $1,050.74$ & 372 & & & & \\
\hline
\end{tabular}

Note. SV: Source of variation; SS: Sum of squares; df: Degree of freedom; MS: Mean squares; F: F-value; FC: F critical value

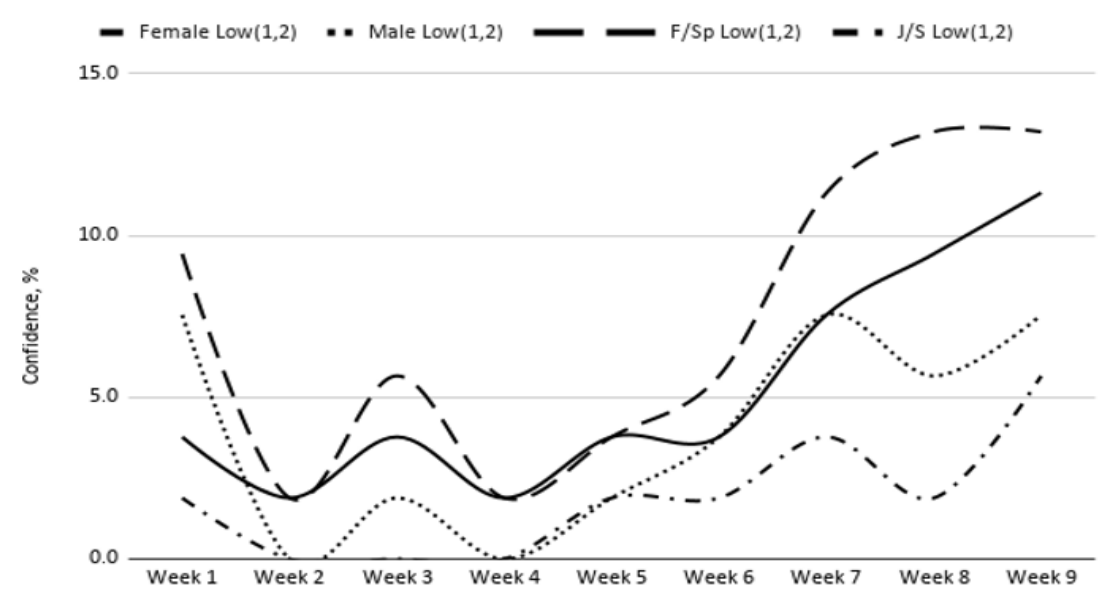

Figure 4. Percentage of the STEM students with low levels of confidence

Finally, Table 5 demonstrates the ANOVA results with respect to the level of confidence and gender. There was a significant difference between the male and female students and their responses to the question "How confident are you today that you will pass this class with a grade B or better?" Summary of means and standard deviations related to Tables 2-5 are given in Table A1 in Appendix B.

\section{Time Series}

Based on the time series descriptive statistical analysis shown in Figure 4, it was found that the prevalence of students with low confidence increased a week before the midsemester exam. The prevalence of low confidence increased in all groups, reaching an average of $9.4 \%$ end of the semester. Serhan (2020) found that $9.68 \%$ of participants said that using Zoom helped them gain confidence in the subject, which is in line with our findings. Freshman and sophomore students experienced the greatest loss of confidence during the semester, reaching 13.2\%. Self-reported low confidence increased from week four onward.

Figure 5 shows that the prevalence of low motivation increased in all groups reaching an average of $6.6 \%$. According to the findings of Serhan's (2020) study, students reported a negative influence on their learning experience and motivation. Freshman and sophomore students lost their motivation more than other groups, reaching $9.4 \%$. The descriptive analysis of the relationship between gender and low motivation showed significant differences between male and female students. Male students started with lower motivation than their female peers. The prevalence of students with low confidence increased a week before the exam. Students started and finished the semester with low motivation.

As shown in Figure 6, approximately $20 \%$ of students reported math anxiety during the semester and the prevalence of math anxiety was much higher at the beginning of the semester, where $25 \%$ to $50 \%$ of students reported math anxiety. The prevalence of math anxiety in male students flattened to around $17 \%$. However, in female students, it decreased to $13 \%$ halfway through the semester, then bounced back to $24 \%$. Freshman and sophomore students reported higher math anxiety than their junior and senior counterparts, averaging $27.4 \%$ and $15.5 \%$, respectively.

According to Figure 7 , an average of $8.7 \%$ of female students reported an increased level of math anxiety due to the COVID-19 pandemic. Poignantly, COVID-19 affected male students more than female students. Male students reported an increased level of math anxiety, $13.2 \%$. An average of $16.7 \%$ of freshman and sophomore students reported increased math anxiety due to COVID19, while an average of 5.5\% of junior and senior students reported this. This result is consistent with Mendoza et al. (2021). Mendoza et al. (2021) claimed that the levels of math anxiety increased due to the COVID-19 pandemic. Also, Ludwig (2021) concluded that high COVID-19 despair had a negative impact on student performance even though they found no correlation between performance and general anxiety towards learning math or remote learning. F/Sp students were more affected than other groups show in Figure 7. 


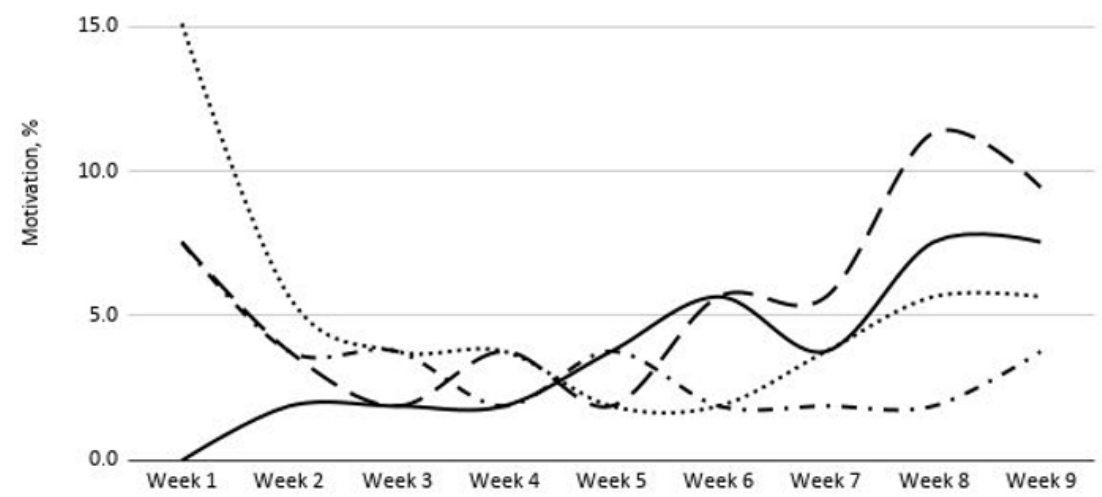

Figure 5. Percentage of the STEM students with low levels of motivation

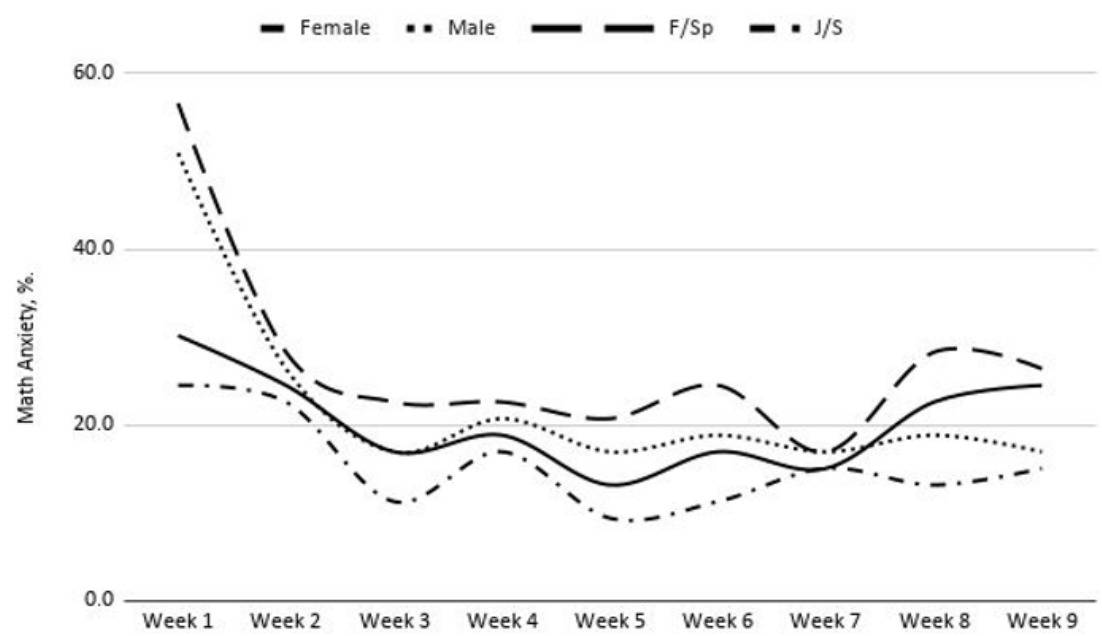

Figure 6. Percentage of the STEM student's math anxiety

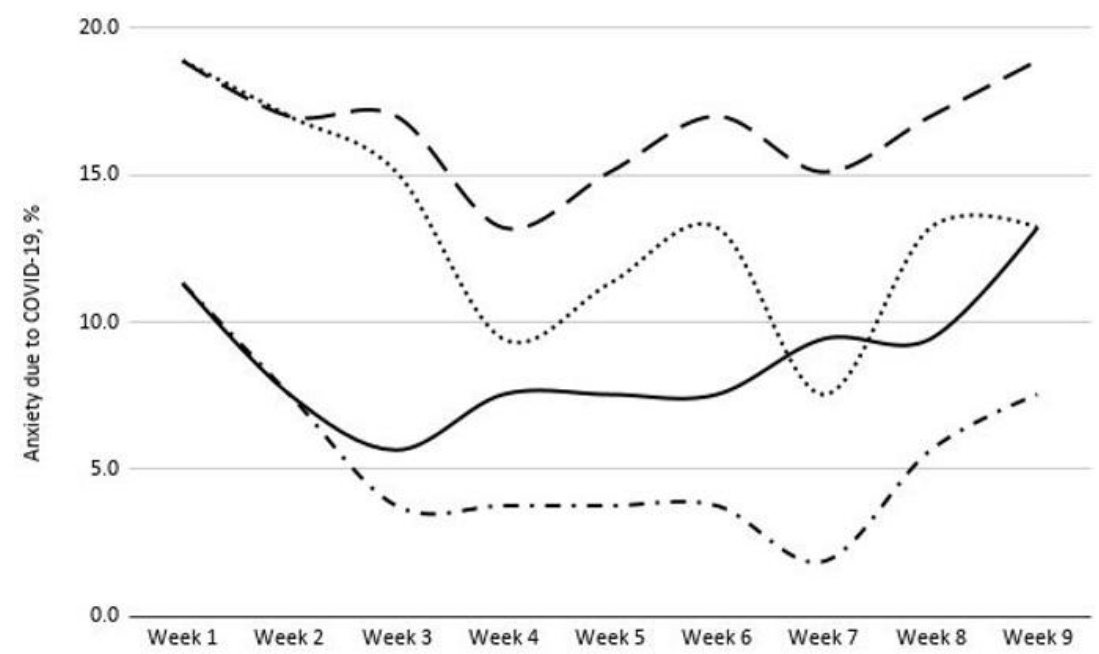

Figure 7. Percentage of the STEM student's who mentioned increased math anxiety due to COVID-19

After analyzing Figure 8, we also observed that female and freshman/sophomore STEM students were more anxious about upcoming grades than other groups. We began surveying students a week before the start of the eight-week summer semester. So, students had two midterm exams during weeks 4 and 7 and their final exam took place during week 9 . Thus, there are two corresponding increases in exam anxiety in Figure 9. The female population reported the highest overall anxiety. Though female students initially reported less anxiety than their male counterparts, as the semester progressed female students' anxiety level surpassed that of the male students reaching 20.8\%. F/Sp students were more anxious for their grades than other groups (Figure 8), and female students had more anxiety for their two midterm exams on weeks 4 and 7 than other groups (Figure 9). 


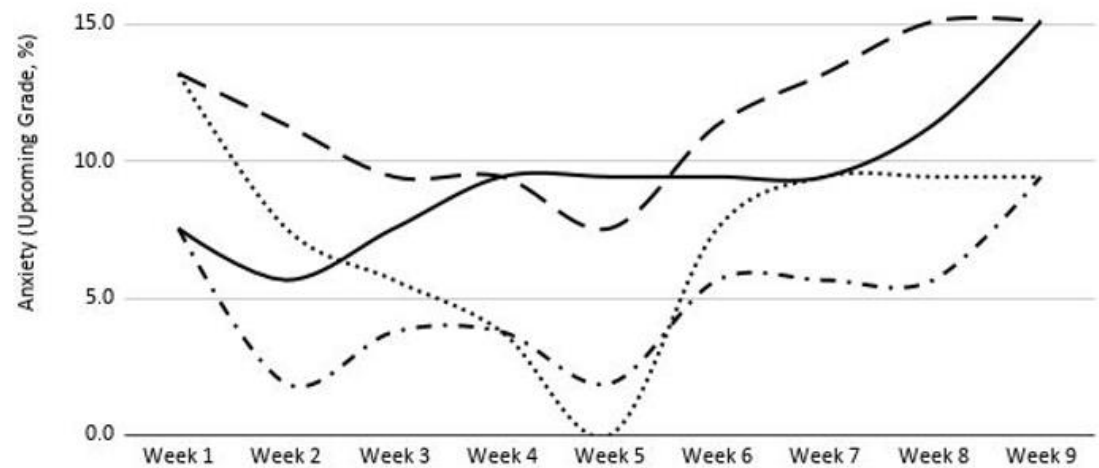

Figure 8. Percentage of the STEM students with high levels of math anxiety for the upcoming grades

25.0

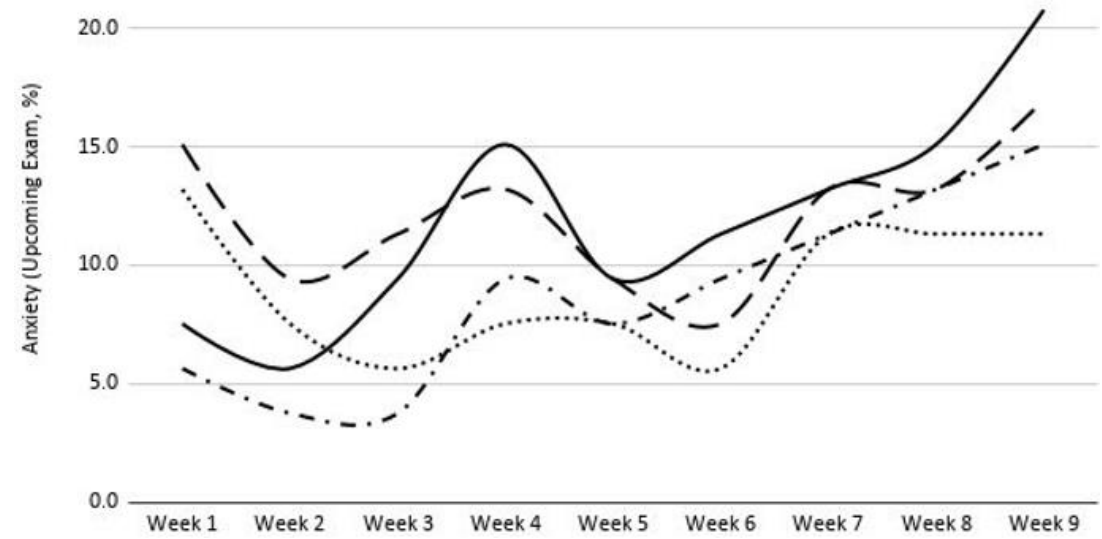

Figure 9. Percentage of the STEM students with high levels of math anxiety for the upcoming exams

Further analysis of time series data showed that the COVID-19 pandemic has substantially decreased the use of supplemental instruction (see Figure A1 in Appendix C). The number of STEM students using UMKC supplemental instruction (SI) dropped from $14.4 \%$ to less than $8 \%$ as the semester progressed. More freshmen and sophomore students sought help from SI than junior and senior students, averaging $11.5 \%$ and $4.2 \%$, respectively. Notably, student utilization of SI surged at week 4 because of the upcoming exam but decreased afterward perhaps because students did not find it useful. Similarly, Figure A2 in Appendix C showed that the COVID-19 pandemic decreased student utilization of UMKC tutoring services. About $8.2 \%$ of STEM students used UMKC tutoring services before the COVID-19 pandemic, but less than $3 \%$ used this resource during the pandemic. Only $1.9 \%$ (3.8\%) of male (female) STEM students used UMKC tutoring during summer 2020. No junior or senior STEM students used UMKC tutoring services during summer 2020. Few students sought help from private tutoring, the highest incidence of which was in freshmen and sophomore students (about 5.7\%).

The COVID-19 pandemic decreased the use of office hours. While there is no data that compares both pre COVID-19 and post COVID-19 data when it comes to math anxiety, some researchers (Candarli \& Yuksel, 2012; Serhan, 2020) found that the use of Zoom had a negative impact on student learning. Notably, most of the students responded that they would have been more comfortable in a traditional classroom setting (Doggett, 2008; Roy et al., 2020). Using Zoom tutoring sessions, on the other hand, dropped considerably professors' workload by $25 \%$ (Sayem et al., 2017). These findings agree with the results of our study. Particularly, only a small percentage of students (2\%-6\%) used Zoom office hours to supplement their learning during the summer 2020 semester (see Figure A3 in Appendix C). Other than the initial high level of anxiety in freshman/sophomore and male STEM students, all groups tended to have low anxiety with respect to upcoming assignments according to Figure A4 in Appendix C with the prevalence of high anxiety between $4 \%$ and $7 \%$.

The COVID-19 pandemic may have increased cooperative learning within the student population. Figure A5 in Appendix C shows that a relatively large percentage of students sought help from their classmates during the pandemic. Namely, an average of $12.1 \%$ of female students, $18.9 \%$ of male students, $24.3 \%$ of freshman/sophomore students, and $6.7 \%$ of junior/senior students sought help from their classmates throughout the semester. Serhan (2020) also found that the usage of Zoom increased students' contact with their classmates, with a mean response range of 1.97 out of 5 regarding classroom interaction. During the semester we also observed that freshman/sophomore STEM students spent less time studying by calculating the weekly average hours of 
study. Female students spent 14.8 hours a week studying calculus, male students spent 15.8 hours, freshman/sophomore students spent 13.8 hours, and junior/senior students spent 19.7 hours (see Figure A6 in Appendix C).

\section{DISCUSSION}

The current COVID-19 pandemic has further complicated the math anxiety of many college students due to changes in coursework, course modality, and poor perceived health (Perz et al., 2020). Researchers have argued that mathematically anxious students tend to move away from studying STEM subjects (Warwick, 2008). The increased anxiety due to COVID-19 may affect their entire trajectory. While the impact of COVID-19 in the field of education is very diverse, less is known about the effects of this crisis on STEM students specifically. This paper investigated time-series changes in each variable (i.e., motivation, anxiety, and confidence) with respect to academic level and gender to understand the effects of the pandemic on STEM students. We investigated the temporal variations in the levels of confidence, motivation, and anxiety during the COVID-19 pandemic. Studies on temporal changes to math anxiety are scarce. The present work aims to fill this gap by analyzing longitudinal survey data associated with math anxiety.

The time series analysis and the inferential statistics of the survey data showed that: (i) levels of motivation and confidence dropped towards the end of the semester (see Figure 4 and Figure 5) which is consistent with Ashcraft (2019). In the mentioned study, Ashcraft (2019) found that the math anxiety correlates negatively with enjoyment of math, self-confidence in math and motivation to learn math (Desender \& Sasanguie, 2021; Grežo \& Sarmány-Schuller, 2018). Additionally, female and F/Sp student was slightly more motivated than their peers (see Figure 1, Figure 2, and Figure 3); (ii) freshman/sophomore and female students had lower confidence compared to male and junior/senior students (see Figure 4 and Figure 5) which is consistent with Bhowmick et al. (2017); (iii) COVID-19 significantly increased the level of math anxiety in all groups of students surveyed (see Figure 6 and Figure 7); (iv) level of math anxiety is highly influenced by upcoming exams and upcoming grades (see Figure 8 and Figure 9) which is consistent with Ashcraft's (2002) study. Ashcraft (2002) found strong interrelation with math anxiety and test anxiety; (v) freshman/sophomore and female students exhibited more anxiety due to an upcoming grade (see Figure 8 and Figure 9). These findings were not directly similar but agree with the findings in some studies that female students tend to be more anxious than males in mathematics (Ashcraft, 2002; Bhowmick et al. 2017; Delage et al., 2021; Rahe \& Quaiser-Pohl, 2021).

There are many questionnaires that claim to measure motivation, self-efficacy, and anxiety. We chose to model our questionnaire after chapter six of Creswell's (2011) Educational Research and applied time series descriptive statistical analysis to our survey data. The key to establishing causality is to analyze each variable on its own and compare the pattern of one population of respondents to that of another. This is illustrated here in relation to gender and academic level.

Our research results indicate that the utilization of math resources, such as tutoring and supplemental instruction, significantly fell due to the COVID-19 pandemic which is consistent with Serhan (2020). Further, the pandemic decreased the use of office hours, but it may have increased cooperative learning between calculus students.

With respect to the general trends, STEM students' math anxiety was highest the week before exams. The prevalence of students who reported low motivation increased from week four onward in freshman and sophomore students and female students. Notably, the prevalence of students with low confidence increased a week before exams. According to the findings of Xie et al. (2019), students' math anxiety might be alleviated by boosting confidence (i.e., self-esteem) and lowering test and general anxiety.

\section{LIMITATIONS OF THE STUDY}

Although this study followed a small population $(n=53)$, it presents apparently consistent data from two different groups of calculus students. That being said, this study has some limitations that should be taken into account when drawing conclusions or generalizing results. One limitation is that we did not collect survey responses before the pandemic, so we could not compare values before and after. The second limitation is that for a small number of students who did not live in the United States, the time zone might become a significant issue that affected their academic performance. We had no control over that aspect of their participation, whether it was due to their time zone, (possibly being in their native country) or the fact that they were residing in a different State within the United States. But this study provides some insights for further research and practice. Moving forward, further research should be conducted on the effect of parameters like ethnicity and age on motivation, self-efficacy, and anxiety. Further study of such parameters would allow educators to better serve students as online learning continues to be a fixture of university education.

Author contributions: All authors have sufficiently contributed to the study, and agreed with the results and conclusions.

Funding: No funding source is reported for this study.

Declaration of interest: No conflict of interest is declared by authors. 


\section{REFERENCES}

Alemany-Arrebola, I., Rojas-Ruiz, G., Granda-Vera, J., \& Mingorance-Estrada, Á. (2020). Influence of COVID-19 on the perception of academic self-efficacy, state anxiety, and trait anxiety in college students. Frontiers in Psychology, 11, 570017. https://doi.org/10.3389/fpsyg.2020.570017

Ashcraft, M. H. (2002). Math anxiety: Personal, educational, and cognitive consequences. Current Directions in Psychological Science, 11(5), 181-185. https://doi.org/10.1111/1467-8721.00196

Ashcraft, M. H. (2019). Models of math anxiety. In I. C. Mammarella, S. Caviola, \& A. Dowker (Eds.), Mathematics anxiety: What is known and what is still to be understood (pp. 1-19). Routledge/Taylor \& Francis Group. https://doi.org/10.4324/97804291999811

Bhowmick, S., Young, J. A., Clark, P. W., \& Bhowmick, N. (2017). Marketing students' mathematics performance: The mediating role of math anxiety on math self-concept and math self-efficacy. Journal of Higher Education Theory and Practice, 17(9), 104117. https://doi.org/10.33423/jhetp.v17i9.1426

Candarli, D., \& Yuksel, H. G. (2012). Students' perceptions of video-conferencing in the classrooms in higher education. ProcediaSocial and Behavioral Sciences, 47, 357-361. https://doi.org/10.1016/j.sbspro.2012. 06.663

Casinillo, L. F., \& Casinillo, E. L. (2020). Econometric evidence on self-determination theory in learning calculus among agribusiness students. The Indonesian Journal of Social Studies, 3(1), 1-12. https://doi.org/10.26740/ijss.v3n1.p1-12

Creswell, J. W. (2011). Educational research: Planning, conducting, and evaluating quantitative and qualitative research. Pearson.

Delage, V., Trudel, G., Retanal, F., \& Maloney, E. A. (2021). Spatial anxiety and spatial ability: Mediators of gender differences in math anxiety. Journal of Experimental Psychology: General. https://doi.org/10.1037/xge0000884

Desender, K., \& Sasanguie, D. (2021). Math anxiety relates positively to metacognitive insight into mathematical decision making. Psychological Research. https://doi.org/10.1007/s00426-021-01511-8

DeVellis, R. F., \& Thorpe, C. T. (2021). Scale development: Theory and applications. SAGE.

Dillman, D. A., Smyth, J. D., \& Christian, L. M. (2009). Internet, mail, and mixed-mode surveys: The tailored design method. John Wiley \& Sons, Inc.

Doggett, A. M. (2008). The videoconferencing classroom: What do students think? Architectural and Manufacturing Sciences Faculty Publications, 44(4), 29-41. https://eric.ed.gov/?id=EJ830487

Forakis, J., March, J. L., \& Erdmann, M. (2020). The impact of COVID-19 on the academic plans and career intentions of future stem professionals. Journal of Chemical Education, 97(9), 3336-3340. https://doi.org/10.1021/acs.jchemed.0c00646

García, E., \& Weiss, E. (2020). COVID-19 and student performance, equity, and US education policy: Lessons from pre-pandemic research to inform relief, recovery, and rebuilding. Economic Policy Institute. https://files.eric.ed.gov/fulltext/ED610971.pdf

Grežo, M., \& Sarmány-Schuller, I. (2018). Do emotions matter? The relationship between math anxiety, trait anxiety, and problemsolving ability. Studia Psychologica, 60(4), 226-244. https://doi.org/10.21909/sp.2018.04.764

Hampton, K., Fernandez, L., Robertson, C., \& Bauer, J. M. (2020). Repercussions of poor broadband connectivity for students in rural and small town michigan. SSRN Electronic Journal. https://doi.org/10.2139/ssrn.3749644

Hensley, L., Avila-Medina, F., Gillespie, T., Lee, H., Masonheimer, A., Nagpal, M., Perry, A., Varzeas, K., \& You, Y. (2020). Compassionate teaching during COVID-19: Key approaches in a college success course. In Rising to the challenge: Navigating COVID-19 as higher education learning center leaders. The learning assistance review (pp. 349-360). National College Learning Center Association.

Johns, C., \& Mills, M. (2021). Online mathematics tutoring during the COVID-19 pandemic: Recommendations for best practices. PRIMUS, 31(1), 99-117. https://doi.org/10.1080/10511970.2020.1818336

Jungic, V. (2020). Making calculus relevant: Final exam in the time of COVID-19. International Journal of Mathematical Education in Science and Technology, 52(4), 609-621. https://doi.org/10.1080/0020739x.2020.1775903

Lancaster, T., \& Cotarlan, C. (2021). Contract cheating by stem students through a file sharing website: A COVID-19 pandemic perspective. International Journal for Educational Integrity, 17, 3. https://doi.org/10.1007/s40979-021-00070-0

Ludwig, J. (2021). Poor performance in undergraduate math: Can we blame it on COVID-19 despair? International Journal of Innovation in Science and Mathematics, 9(3), 31-40.

Marpa, E. (2021). Technology in the teaching of mathematics: An analysis of teachers' attitudes during the COVID-19 pandemic. International Journal on Studies in Education, 3(2), 92-102. https://doi.org/10.46328/ijonse.36

Mendoza, D., Cejas, M., Rivas, G., \& Varguillas, C. (2021). Anxiety as a prevailing factor of performance of university mathematics students during the COVID-19 pandemic. The Education and Science Journal, 23(2), 94-113. https://doi.org/10.17853/19945639-2021-2-94-113

Midcalf, L., \& Boatwright, P. (2020). Teacher and parent perspectives of the online learning environment due to COVID-19. The Delta Kappa Gamma Bulletin, 87(1), 24-34.

Mubeen, S., \& Reid, N. (2014). The measurement of motivation with science students. European Journal of Educational Research 3(3), 129-144. https://doi.org/10.12973/eu-jer.3.3.129 
Ng, D. C., Mahmoud, S. S., Hald, E. S., \& Fang, Q. (2020). Overcoming challenges in teaching calculus remotely during COVID-19 pandemic. https://doi.org/10.21203/rs.3.rs-43728/v1

Perz, C., Lang, B., \& Harrington, R. (2020). Validation of the fear of COVID-19 scale in a US college sample. International Journal of Mental Health and Addiction, 20(1), 273-283. https://doi.org/10.1007/s11469-020-00356-3

Rahe, M., \& Quaiser-Pohl, C. (2021). Can (perceived) mental-rotation performance mediate gender differences in math anxiety in adolescents and young adults? Mathematics Education Research Journal. https://doi.org/10.1007/s13394-021-00387-6

Reinhold, F., Schons, C., Scheuerer, S., Gritzmann, P., Richter-Gebert, J., \& Reiss, K. (2021). Students' coping with the selfregulatory demand of crisis-driven digitalization in university mathematics instruction: Do motivational and emotional orientations make a difference? Computers in Human Behavior, 120, 106732. https://doi.org/10.1016/j.chb.2021.106732

Roy, H., RaY, K., Saha, S., \& Ghosal, A. K. (2020). A study on students' perceptions for online Zoom-app based flipped class sessions on anatomy organised during the lockdown period of COVID-19 epoch. Journal of Clinical \& Diagnostic Research, 14(6), 1-4. https://doi.org/10.7860/JCDR/2020/44869.13797

Sabates, R., Carter, E., \& Stern, J. (2021). Using educational transitions to estimate learning loss due to COVID-19 school closures: The case of complementary basic education in Ghana. International Journal of Educational Development, 82, 102377. https://doi.org/10.1016/j.ijedudev.2021.102377

Saw, G. K., Chang, C.-N., Lomelí, U., \& Zhi, M. (2020). Fall enrollment and delayed graduation among stem students during the COVID-19 pandemic. Network for Research and Evaluation in Education. https://nreeducation.wordpress.com/2020/07/15/fallenrollment-and-delayed-graduation-among-stem-students-during-the-covid-19-pandemic/

Sayem, A. S. M., Taylor, B., McClanachan, M., \& Mumtahina, U. (2017, December). Effective use of Zoom technology and instructional videos to improve engagement and success of distance students in engineering. In 28th Annual Conference of the Australasian Association for Engineering Education (pp. 926-931). http://www.aaee.net.au/index.php/program

Serhan, D. (2020). Transitioning from face-to-face to remote learning: Students' attitudes and perceptions of using Zoom during COVID-19 pandemic. International Journal of Technology in Education and Science, 4(4), 335-342. https://doi.org/10.46328/ijtes.v4i4.148

Sevindir, H., Yazici, C., \& Yazici, V. (2014). Mathematics anxiety: A case study for kocaeli university. Procedia-Social and Behavioral Sciences, 152, 637-641. https://doi.org/10.1016/j.sbspro.2014.09.255

Tobias, S., \& Weissbrod, C. (1980). Anxiety and mathematics: An update. Harvard Educational Review, 50(1), 63-70. https://doi.org/10.17763/haer.50.1.xw483257j6035084

Voica, C., Singer, F., \& Stan, E. (2020). How are motivation and self-efficacy interacting in problem-solving and problem-posing? Educational Studies in Mathematics, 105(3), 487-517. https://doi.org/10.1007/s10649-020-10005-0

Warwick, J. (2008). Investigating mathematical anxiety among non-specialist undergraduate students. Mathitudes, 1(1), 1-9.

Xie, F., Xin, Z., Chen, X., \& Zhang, L. (2019). Gender difference of Chinese high school students' math anxiety: The effects of selfesteem, test anxiety and general anxiety. Sex Roles: A Journal of Research, 81(3-4), 235-244. https://doi.org/10.1007/s11199018-0982-9 


\section{APPENDIX A}

\section{A Series of Six Questions}

QUESTION 1: Please rank the level of math anxiety you are feeling today: 1-7 (1=the lowest level of anxiety, 7=the highest level of anxiety)
a. Upcoming assignment
b. Upcoming midterm or final exam
c. Upcoming Zoom meeting
d. Your anticipated grade in this course
e. Other reasons (specify)
f. I am not feeling anxious about math today (enter Yes if this is the case. Otherwise, leave blank)
Copy this and paste it in the following box to enter your answers: (b) (c) (d) (e) (f)

QUESTION 2: What type of help did you seek for your math anxiety this week? (Enter 1 for all that apply and 0 for those that don't)
a. Supplemental Instruction
b. UMKC tutoring
c. Office hours
d. Online tutoring (Net tutor)
e. Classmates
f. Private tutor
g. UMKC Counseling Center (https://info.umkc.edu/counseling-services/)
h. Other (specify)
i. I did not seek any help
j. I did not have any math anxiety this week
Copy this and paste it in the following box to enter your answers: (a) (b) (c) (d) (e) (f) (g) (h) (i) (j)

QUESTION 3: Aside from Zoom meetings and My Math Lab videos, how many hours have you approximately spent studying for this class this week?

QUESTION 4: How would you rate your desire to study this week? (1-7) 1 = no desire to study, 7 = very motivated to study).

QUESTION 5: How confident are you today that you will pass this class with a B or better? ( $1=$ not confident at all, $7=$ very confident).

QUESTION 6: Are you or any of your family members currently affected by COVID-19 in a way that is influencing your ability to succeed in this class or increasing your math anxiety? Enter Yes/No. Also, include any comments if you would like to. 


\section{APPENDIX B}

\section{Supporting Result for the ANOVA Testing}

Table A1. Means and standard deviations for the survey items and performance variables

\begin{tabular}{|c|c|c|c|}
\hline & Means & Standard deviations & \\
\hline Female & 56.72 & 15.29 & For Table 2 \\
\hline Male & 35.31 & 17.20 & For Table 2 \\
\hline Freshman/sophomore & 25.90 & 2.78 & For Table 3 \\
\hline Junior/senior & 16.04 & 8.52 & For Table 3 \\
\hline Female & 4.94 & 1.75 & For Table 5 \\
\hline Male & 4.40 & 1.59 & For Table 5 \\
\hline Freshman/sophomore & 4.62 & 1.67 & For Table 4 \\
\hline
\end{tabular}




\section{APPENDIX C}

\section{Supporting Results for the Time Series Analysis}

20.0

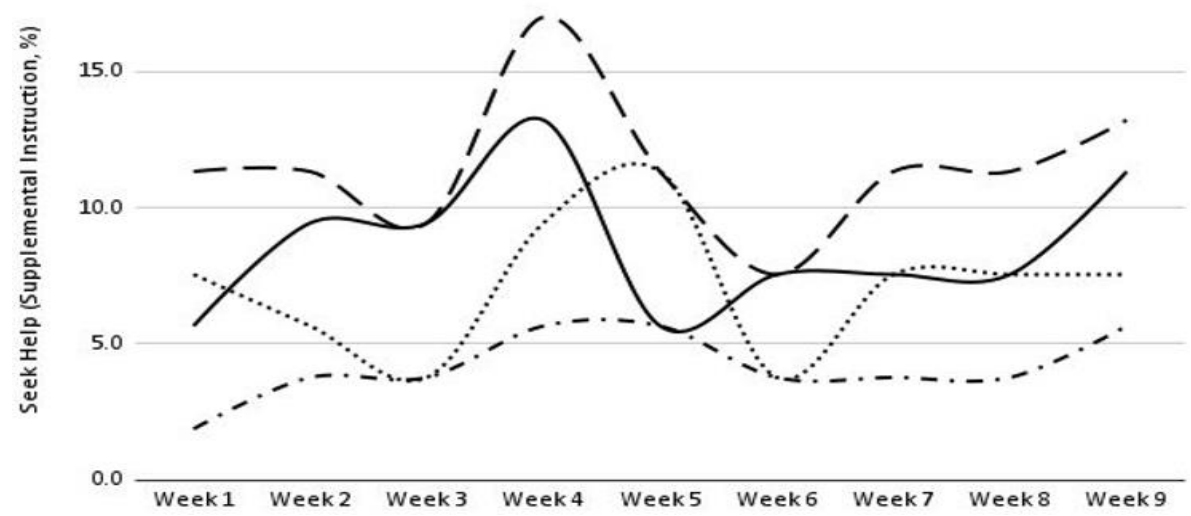

Figure A1. Prevalence of the STEM students seek help from supplemental instruction

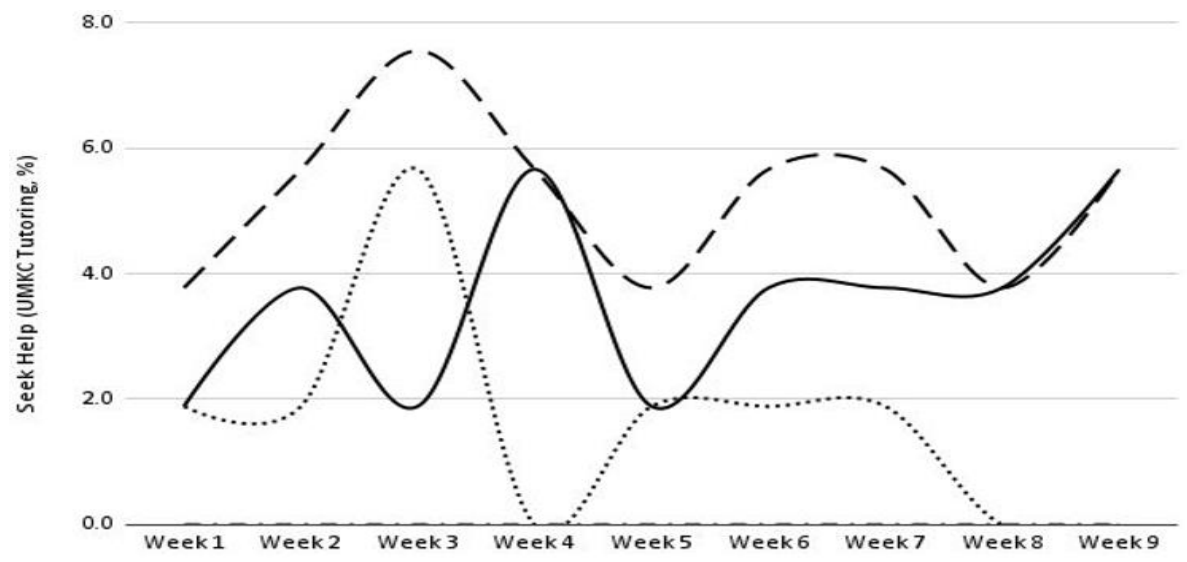

Figure A2. Prevalence of the STEM students seek help from UMKC tutoring

Note. Students sought help mostly on week 4 (Figure A1) and one week before (Figure A2). J/S STEM students less interested than other groups (Figure A2). And F/Sp more sought help from Supplemental instruction (Figure A1) and UMKC tutoring (Figure A2). 


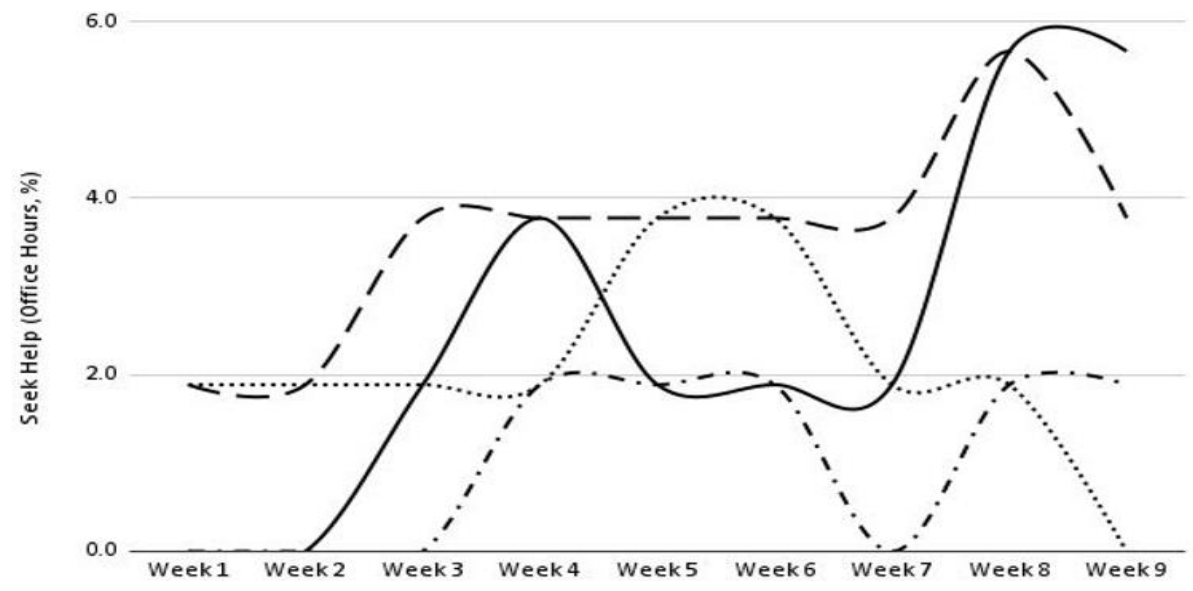

Figure A3. Prevalence of the STEM students seek help from office hours

20.0

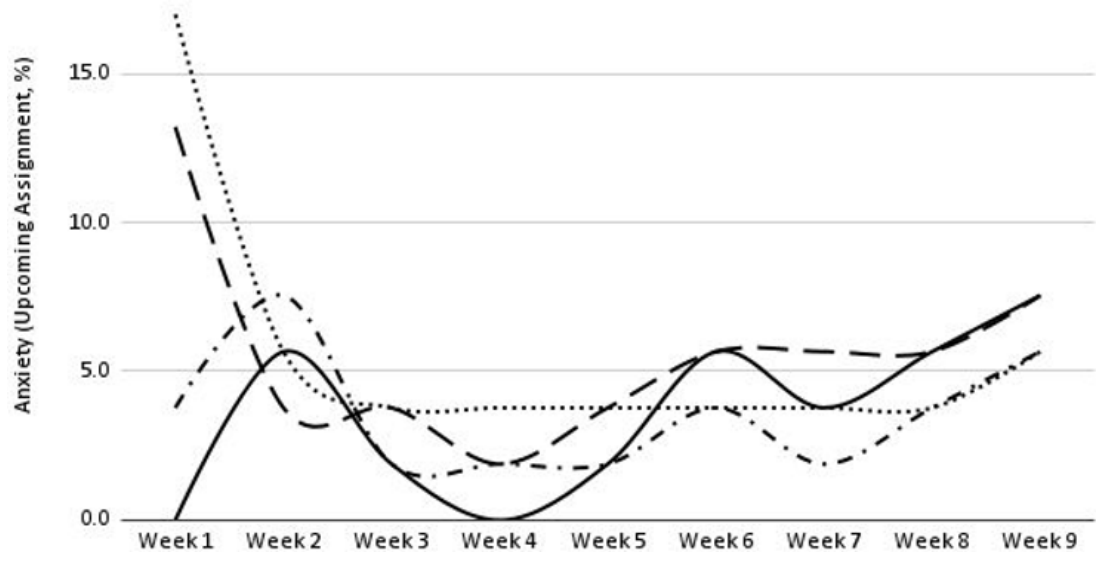

Figure A4. Percentage of the STEM students with high levels of math anxiety for upcoming assignment

Note. All group interested to seek help from office hours around exam weeks (Figure A3), and male students were more anxious for their upcoming assignment on the first week of the semester and F/Sp followed the male groups (Figure A4). 


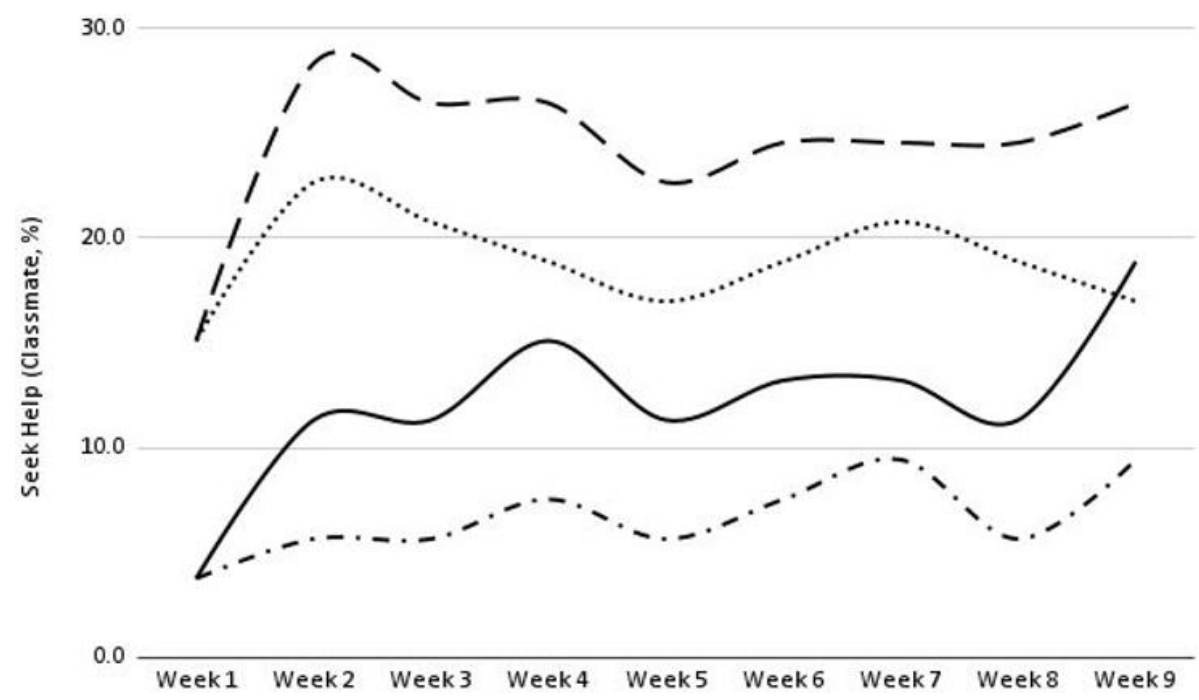

Figure A5. Prevalence of the STEM students seek help from classmates for calculus during the semester

30.0

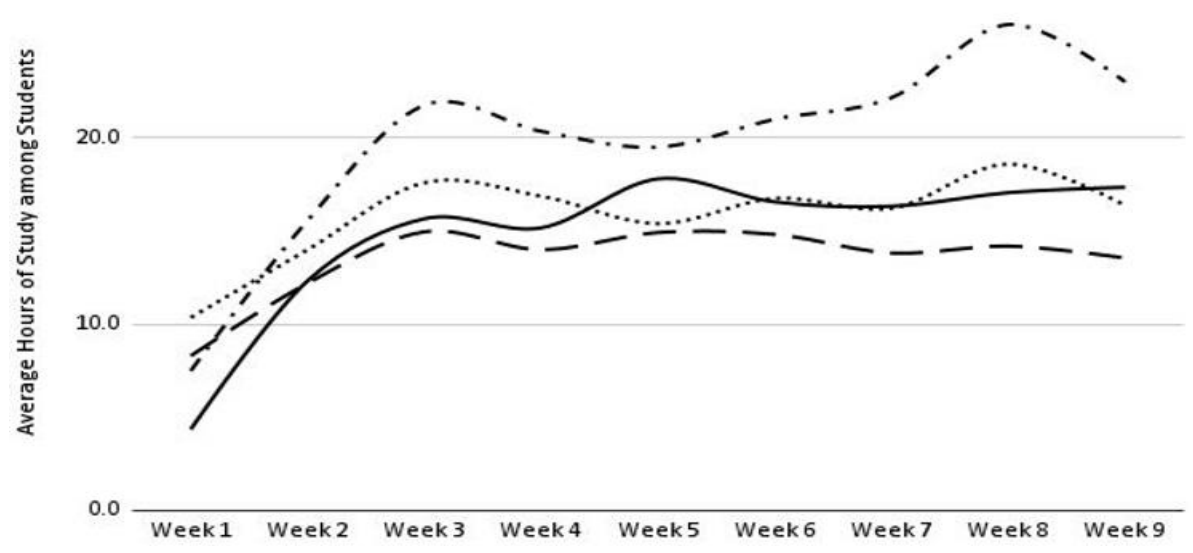

Figure A6. Prevalence of the STEM students average study hours for calculus during the semester

Note. All group preferred to study with their peers except J/S (Figure A5). J/S students studied on their Calculus more than other groups (Figure A6) 